\title{
Retrospective study of survival rate according to the type of dental restoration of proximal caries in maxillary primary incisors
}

\author{
Doo-Soo Kim ${ }^{1}$, Nan-Young Lee ${ }^{1,2}$, Myeong-Kwan Jih ${ }^{1,2 \star}$, and Ok-Hyung Nam ${ }^{3}$ \\ ${ }^{1}$ Department of Pediatric Dentistry, School of Dentistry, Chosun University, Gwangju, Republic of Korea \\ ${ }^{2}$ Oral Biology Research Institute, Chosun University, Gwangju, Republic of Korea \\ ${ }^{3}$ Department of Pediatric Dentistry, Kyung Hee University School of Dentistry, Seoul, Republic of Korea
}

Recently, owing to the development of restorative materials, various materials have been used for the restoration of maxillary primary incisors. Dental materials used for restoring the proximal caries of maxillary primary incisors include composite resin, a resin strip crown, and a zirconium crown. Each restoration material has its own advantages and disadvantages. However, only a few studies have compared the survival rate of each material. Therefore, in this study, two-year survival rates were surveyed by analyzing approximately 470 teeth treated using various restorative materials. The results of this study may be helpful in the selection of materials for the treatment of proximal caries in maxillary primary incisors.

Key Words: Dental caries, Dental materials, Primary teeth, Incisor

@) This is an open-access article distributed under the terms of the Creative Commons Attribution Non-Commercial License (http://creativecommons.org/licenses/by-nc/4.0) which permits unrestricted noncommercial use, distribution, and reproduction in any medium, provided the original work is properly cited.

\section{서 론}

유치열기에 일어나는 유절치의 상아질 우식은 종종 급속도로 진행되어 광범위한 치질의 파괴, 치수염으로 인한 통증, 근단농 양 등을 일으킨다[1]. 뿐만 아니라 유절치부의 심한 우식은 심미 성의 훼손, 혀 내밀기와 같은 구강악습관, 발음상의 문제, 심리 적인 문제, 저작 능력의 저하, 수직고경의 감소 등 광범위한 문 제와 관련이 있다[2]. 특히 심미성의 문제는 부모들이 어린이와 함께 치과에 내원하는 가장 중요한 이유 중 하나이다[2].

최근 수복 재료의 발달로 치아우식 처치를 위한 다양한 재료 들이 사용되고 있다. 유절치부 수복을 위해 사용되고 있는 재료 로는 복합레진, 글래스아이오노머, resin strip crown, 지르코니 아 크라운 등이 있으며 각 수복재료마다 나름의 장단점이 존재
하여 신중한 선택이 요구된다[3,4].

유절치부 수복 재료를 선택하는 일은 많은 임상의들에게 어 려운 문제이다[5]. 유절치부의 적절한 수복 재료를 선택하기 위 해 재료의 강도, 수복 용이성, 환자의 협조도, 환자의 우식 민감 성, 심미성, 술자의 숙련도 등이 고려되어야 하지만 아직 재료 선택에 대한 일관된 지침이 확립되지 않아 임상의의 선호도에 따라 수복재료가 사용되고 있다[6].

경미하거나 중등도의 유절치부 우식 병소에서 전통적으로 복 합레진 직접 수복법은 가장 오랫동안 사용되어온 수복 방법이 다. 하지만 수분에 민감하고 중합수축으로 인한 변연부의 미세 누출의 가능성이 있으며 이는 이차우식 발생 가능성을 높일 수 있다[7].

글래스아이오노머 시멘트는 치질과 화학적 결합을 이루고 불

Received November 13, 2019; Accepted November 18, 2019

*Corresponding author: Myeong-Kwan Jih, Department of Pediatric Dentistry, School of Dentistry, Chosun University, 303 Pilmun-daero, Dong-gu, Gwangju 61452, Republic of Korea.

Tel: +82-62-220-3868, Fax: +82-62-225-8240, E-mail: mdenti@chosun.ac.kr 
소를 방출하여 항우식 작용을 가지는 수복재료로 다양한 용도 로 이용되고 있다. 하지만 조작성이 좋지 않고 기계적 성질과 심 미성이 부족하여 영구수복 재료로써의 한계를 가지며 최근 유 절치부 수복에는 사용이 감소하는 추세이다[8].

Resin strip crown은 매우 심미적인 수복 방법으로 부분적인 파절 시에도 손쉽게 수리가 가능해 많은 임상의들에게 유절치 부 치료 시 첫 번째로 선택되고 있다[3]. 하지만 술식의 기술적 민감도가 크고 수분이나 출혈 조절에 어려움을 겪을 수 있다는 단점을 가지고 있다[7].

유치를 위한 지르코니아 크라운은 2010년 처음으로 상업화 가 이루어졌다. 우수한 심미성과 기계적 특성으로 이후 소아치 과에서 활발하게 사용되고 있으나 많은 치질 삭제량과 크라운 변연 조절의 한계는 단점으로 남아있다[9].

과거 많은 연구들에서 유절치부 심미수복에 사용되는 개별 재료들이 소개되었으나 재료들의 물리적 특성이나 생존율을 비 교하고 평가한 연구는 거의 없었다. 본 연구에서는 상악 유절치 인접면 우식 치료에 사용된 수복물들의 2년 생존율을 평가하고 각 수복물들의 실패 양상을 분석해보고자 한다.

\section{대상 및 방법}

\section{연구 대상}

2014년부터 2016년까지 조선대학교 치과병원 소아치과에 내원하여 상악 유절치의 인접면 우식으로 수복 치료를 받은 1 세 이상 4세 미만의 환자들을 대상으로 전자의무기록지와 방사선 사진이 분석되었다. 이들 중 다음에 해당하는 환자들은 제외되 었다. (1) 전자의무기록지와 방사선 사진이 부정확 또는 불명확 하여 분석에 제한이 되는 환자; (2) 치료를 받고 재내원하지 않 은 환자; (3) 치료를 받은 후 외상이나 생리적 치근의 흡수로 인 해 해당 치아가 탈락한 경우; (4) 치료 전, 치아에 농루, 근단농 양, 근단병소 또는 병적 동요가 존재하는 경우. 조사한 총 환자 수는 241명, 치아의 개수는 469개였다.

\section{연구 방법}

\section{조사 대상 선정}

전자의무기록 평가: 전자의무기록을 이용하여 환자들의 나 이, 치료된 치아의 종류, 근심면과 원심면으로 나눈 우식의 위 치, 수복 전 치수치료 여부, 추적 조사 기간 동안 발생한 합병증 의 종류와 발생 시기에 대한 기록이 수집되었다. 치과용 복합 레진(Filtek ${ }^{\mathrm{TM}}$ Z250; 3M ESPE, St. Paul, MN, USA), resin strip crown (Pediatric Strip Crown Forms, Filtek ${ }^{\mathrm{TM}}$ Z350; 3M
ESPE), 지르코니아 크라운(NuSmile ${ }^{\circledR}$ ZR Zirconia; NuSmile, Houston, TX, USA)에 대해 합병증의 종류와 발생 시기가 조사 되었다.

방사선 사진 평가: 우식 치료 전의 방사선 사진에서 인접면의 상아질 우식이 확인되는 치아들을 연구 대상으로 하였다. 추적 조사 기간 동안 방사선 사진을 확인하여 합병증의 발생 유무를 관찰하였다.

수복물 실패의 분류: 다음과 같은 합병증이 발생할 경우 실패 로 간주하고 생존율 평가에 반영되었다. (1) 이차우식; (2) 수복 물의 파절; (3) 수복물의 탈락; (4) 치경부 파절; (5) 치근의 비정 상적인 흡수 또는 방사선 투과상의 병소.

추적조사: 환자가 재내원한 날들의 전자의무기록과 방사선 사진을 평가하였다. 24 개월까지의 추적조사 기간 동안 합병증 발생 여부를 관찰하였으며 합병증이 발생하면 그 시기를 기록 하였다.

자료분석: 다음과 같은 내용들에 대해 통계분석 시행하였다. (1) 24개월 동안의 수복재료별 생존율; (2) 치아의 종류를 유중 절치(A), 유측절치(B)로 나누어 이에 따른 수복물의 생존율; (3) 우식이 근심면 또는 원심면 중에 한 면에만 이환된 경우(one side)와 근원심면 모두에 이환된 경우(both sides)로 나누어 이 에 따른 수복물의 생존율; (4) 치수치료 시행 여부에 따른 수복 물의 생존율; (5) 수복재료와 수복실패 종류의 상관관계. 모든 통계 분석은 IBM SPSS ver. 18.0 (IBM Corp., Armonk, NY, USA)을 이용하였으며 수복재료와 수복실패 종류의 상관관계 를 위해서 Fisher's exact test가, 그 외의 다른 모든 분석에는 Kaplan-Meier method가 사용되었다.

\section{결 과}

\section{유전치 인접면 우식의 수복재료에 따른 생존율}

추적조사 하는 동안 각 수복물의 합병증 발생여부와 발생 시 기를 조사하고 생존율을 분석하였다. 합병증의 발생 시기를 분 석할 수 있는 생존율 그래프에서 복합레진 수복에 비해 resin strip crown과 지르코니아 크라운의 합병증 발생이 적었으 며 이는 통계적으로 유의한 차이를 보였다(Fig. 1). Resin strip crown (26.2\%)과 지르코니아 크라운(20.6\%)은 복합레진 수복 (51.3\%)에 비해 낮은 수복 실패율을 보였다(Table 1). 복합레진 수복은 24 개월 동안의 추적조사에서 평균 약 18 개월 동안 생 존하여 각각 21개월과 22개월의 평균 생존기간을 나타낸 resin strip crown, 지르코니아 크라운과 통계적으로 유의한 차이를 나타냈다(Table 2). 


\section{치아의 종류에 따른 각 수복재료의 생존율}

치아의 종류를 유중절치 $(\mathrm{A})$, 유측절치(B)로 나누어 이에 따 른 수복물의 생존율을 분석하였다. 모든 수복물에서 치아의 종 류에 따라 통계적으로 유의미한 차이가 관찰되지 않았다(Table 3-5).

\section{편측 및 양측성 인접면 우식의 각 수복재료의 생존율}

인접면 우식을 근심면 또는 원심면 중에 한 면에만 이환된 경

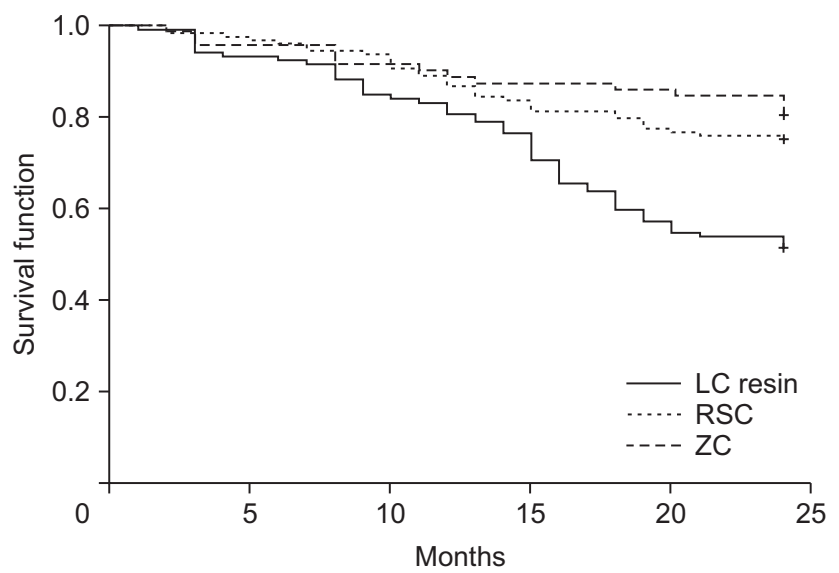

Fig. 1. Survival estimates of different restorative materials over time. LC resin, light curing composite resin; RSC, resin strip crown; ZC, zirconia crown.

Table 1. The number of failures and successes on different restorative dental materials

\begin{tabular}{lccc}
\hline \multirow{2}{*}{$\begin{array}{c}\text { Restorative } \\
\text { material }\end{array}$} & No. of teeth & Failure & Success \\
\cline { 2 - 4 } & & n (\%) & n (\%) \\
\hline LC resin & 113 & $58(51.3)$ & $55(48.7)$ \\
RSC & 122 & $32(26.2)$ & $90(73.8)$ \\
ZC & 68 & $14(20.6)$ & $54(79.4)$ \\
\hline
\end{tabular}

LC resin, light curing composite resin; RSC, resin strip crown; ZC, zirconia crown.
우(편측)와 근원심면 모두에 이환된 경우(양측)로 나누어 이에 따른 수복물의 생존율을 평가하였다. 복합레진 수복에서 편측 에 이환된 경우 $42.9 \%$, 양측에 이환된 경우 $59.6 \%$ 의 실패율을 나타내어 차이를 보였으며 통계적으로 유의하였다. Resin strip crown과 지르코니아 크라운에서는 편측 및 양측성 인접면 수 복물의 실패율에 유의미한 차이를 나타내지 않았다(Table 6-8).

\section{치수치료 시행 여부에 따른 각 수복재료의 생존율}

치수치료 시행 여부를 전자의무기록지와 방사선 사진을 이용 하여 조사하고 이에 따른 각 수복재료들의 생존율을 분석하였 다. 지르코니아 크라운의 경우 모든 표본에서 수복 전 치수치료 가 시행되어 통계분석에서 제외되었다. 복합레진 수복에서 치 수치료를 시행한 경우 $73.9 \%$ 의 실패율을 나타내어 $45.6 \%$ 를 기 록한 치수치료를 시행하지 않은 경우보다 높은 실패율을 나타 냈으며 이는 통계적으로 유의하였다. Resin strip crown에서는 통계적으로 유의한 차이가 없었다(Table 9, 10).

\section{수복재료와 수복실패 종류의 상관관계}

수복재료와 수복실패 종류간의 상관관계를 분석하기 위해 Fisher's exact test를 수행하였다. 각 수복재료별로 실패요인에 차이를 나타냈으며 복합레진 수복은 이차우식과 수복물의 탈락 이, resin strip crown은 수복물의 파절과 탈락이, 그리고 지르 코니아 크라운은 치경부 파절의 경우가 가장 많았으며 통계적

Table 3. Number of failures and successes on tooth type of primary tooth with $\mathrm{LC}$ resin treatment

\begin{tabular}{cccc}
\hline \multirow{2}{*}{ Tooth type } & No. of teeth & Failure & Success \\
\cline { 3 - 4 } & & $\mathbf{n}(\%)$ & $\mathbf{n}(\%)$ \\
\hline A & 54 & $32(59.3)$ & $22(40.7)$ \\
B & 59 & $26(44.1)$ & $33(55.9)$ \\
\hline
\end{tabular}

Kaplan-Meier method (no significant difference, $p>0.05$ ).

LC resin, light curing composite resin; A, maxillary primary central incisor; B, maxillary primary lateral incisor.

Table 2. Mean survival periods in relation to dental restorative materials

\begin{tabular}{|c|c|c|c|c|}
\hline \multirow{2}{*}{ Restorative material } & \multirow{2}{*}{ Mean survival (mo) } & \multirow{2}{*}{ Standard error } & \multicolumn{2}{|c|}{$95 \%$ confidence interval } \\
\hline & & & Lower bound & Upper bound \\
\hline LC resin & $18.442^{\mathrm{a}}$ & 0.651 & 17.166 & 19.719 \\
\hline RSC & $20.951^{\mathrm{b}}$ & 0.537 & 19.899 & 22.003 \\
\hline $\mathrm{ZC}$ & $21.676^{\mathrm{b}}$ & 0.724 & 20.257 & 23.096 \\
\hline
\end{tabular}

Kaplan-Meier method (a,b: same letters are not significantly different, $p>0.05$ ).

LC resin, light curing composite resin; RSC, resin strip crown; ZC, zirconia crown. 
Table 4. Number of failures and successes on tooth type of primary tooth with resin strip crown

\begin{tabular}{cccc}
\hline \multirow{2}{*}{ Tooth type } & No. of teeth & Failure & Success \\
\cline { 3 - 4 } & & n (\%) & n (\%) \\
\hline A & 78 & $20(25.6)$ & $58(74.4)$ \\
B & 44 & $12(27.3)$ & $32(72.7)$ \\
\hline
\end{tabular}

Kaplan-Meier method (no significant difference, $p>0.05$ ).

A, maxillary primary central incisor; B, maxillary primary lateral incisor.

Table 5. Number of failures and successes on tooth type of primary tooth with zirconia crown

\begin{tabular}{cccc}
\hline \multirow{2}{*}{ Tooth type } & No. of teeth & Failure & Success \\
\cline { 3 - 4 } & & $\mathbf{n}(\%)$ & $\mathbf{n}(\%)$ \\
\hline A & 43 & $8(18.6)$ & $35(81.4)$ \\
B & 25 & $6(24.0)$ & $19(76.0)$ \\
\hline
\end{tabular}

Kaplan-Meier method (no significant difference, $p>0.05$ ).

A, maxillary primary central incisor; B, maxillary primary lateral incisor.

Table 6. Number of failures and successes on caries type of primary tooth with LC resin treatment

\begin{tabular}{lccc}
\hline \multirow{2}{*}{ Caries type } & No. of teeth & Failure & Success \\
\cline { 3 - 4 } & & $\mathbf{n}(\%)$ & $\mathbf{n}(\%)$ \\
\hline One side $^{\mathrm{a}}$ & 56 & $24(42.9)$ & $32(57.1)$ \\
Both sides $^{\mathrm{b}}$ & 57 & $34(59.6)$ & $23(40.4)$ \\
\hline
\end{tabular}

Kaplan-Meier method (a,b: significant difference, $p<0.05$ ).

One side, mesial or distal one side surface caries; both sides, mesial and distal both side surface caries.

Table 7. Number of failures and successes on caries type of primary tooth with resin strip crown

\begin{tabular}{lccc}
\hline \multirow{2}{*}{ Caries type } & No. of teeth & Failure & Success \\
\cline { 3 - 4 } & & $\mathbf{n}(\%)$ & $\mathbf{n}(\%)$ \\
\hline One side & 43 & $12(27.9)$ & $31(72.1)$ \\
Both sides & 79 & $20(25.3)$ & $59(74.7)$ \\
\hline
\end{tabular}

Kaplan-Meier method (no significant difference, $p>0.05$ ).

One side, mesial or distal one side surface caries; both sides, mesial and distal both side surface caries.

으로 유의하였다(Table 11).

\section{고 찰}

본 연구에서 가장 어려웠던 점은 연구 대상자와 대상 치아의
Table 8. Number of failures and successes on caries type of primary tooth with zirconia crown

\begin{tabular}{lccc}
\hline \multirow{2}{*}{ Caries type } & No. of teeth & Failure & Success \\
\cline { 3 - 4 } & & $\mathbf{n}(\%)$ & n (\%) \\
\hline One side & 22 & $5(22.7)$ & $17(77.3)$ \\
Both sides & 46 & $9(19.6)$ & $37(80.4)$ \\
\hline
\end{tabular}

Kaplan-Meier method (no significant difference, $p>0.05$ ).

One side, mesial or distal one side surface caries; both sides, mesial and distal both side surface caries.

Table 9. Number of failures and successes depending on RCT of primary tooth with LC resin treatment

\begin{tabular}{cccc}
\hline \multirow{2}{*}{$\begin{array}{c}\text { Whether RCT } \\
\text { or not }\end{array}$} & No. of teeth & Failure & Success \\
\cline { 3 - 4 } & 23 & n (\%) & n (\%) \\
\hline Yes $^{\mathrm{a}}$ & 90 & $41(73.9)$ & $6(26.1)$ \\
No $^{\mathrm{b}}$ & & $45.6)$ & $49(54.4)$ \\
\hline
\end{tabular}

Kaplan-Meier method (a,b: significant difference, $p<0.05$ ).

$\mathrm{RCT}$, root canal treatment; LC resin, light curing composite resin.

Table 10. Number of failures and successes depending on RCT of primary tooth with resin strip crown

\begin{tabular}{cccc}
\hline \multirow{2}{*}{$\begin{array}{c}\text { Whether RCT } \\
\text { or not }\end{array}$} & No. of teeth & Failure & Success \\
\cline { 3 - 4 } & & $\mathbf{n}(\%)$ & $\mathbf{n}(\%)$ \\
\hline Yes & 64 & $16(25.0)$ & $48(75.0)$ \\
No & 58 & $16(27.6)$ & $42(72.4)$ \\
\hline
\end{tabular}

Kaplan-Meier method (no significant difference, $p>0.05$ ). RCT, root canal treatment.

선정이었다. 상악 유절치의 생리적 탈락시기가 만 7-8세인 점 [10]과 본 연구의 추적관찰 시기가 2년인 점을 고려하여 1세 이 상 4세 미만의 어린이를 대상으로 하였다. 또한 본 연구는 다양 한 수복재료의 수복 후 발생하는 합병증을 조사하는 연구이었 으므로 치료 전 치아에 농루, 근단농양, 근단병소 또는 병적 동 요가 존재하는 경우와 치료를 받은 후 외상이나 생리적 치근의 흡수로 인해 치아가 탈락한 경우는 제외되었다. 추적관찰 기간 에 방사선 사진이 존재하지 않는 경우도 제외되었는데 이는 근 단부의 병소나 이차우식이 생겼음에도 술자가 인지하지 못한 경우도 있을 수 있기 때문이었다.

본 연구에서 복합레진 수복은 resin strip crown, 지르코니 아 크라운과 비교하여 24개월 생존율이 낮게 나타났다. 특히 치 수치료를 시행한 경우에는 복합레진 수복의 24 개월 생존율이 $26.1 \%$ 로 치수치료를 시행하지 않은 경우의 생존율 $54.4 \%$ 와 큰 차이를 나타냈다. 이러한 결과를 바탕으로 상악유절치부의 경우 resin strip crown이나 지르코니아 크라운이 복합레진 수복에 
Table 11. The failure type of upper anterior tooth restoration depending on restorative materials

\begin{tabular}{lccccc}
\hline & \multicolumn{3}{c}{ Failure type } \\
\cline { 2 - 6 } $\begin{array}{c}\text { Restorative } \\
\text { material }\end{array}$ & Secondary caries & Restoration fracture & Restoration fall out & Cervical fracture & $\begin{array}{c}\text { Abnormal root } \\
\text { resorption or } \\
\text { radiographic lesion }\end{array}$ \\
\hline LC resin & $26^{* * *}$ & 5 & $24^{* * *}$ & 0 & 3 \\
RSC & 4 & $14^{* * *}$ & $9^{* * *}$ & 2 & 3 \\
ZC & 1 & 0 & 1 & $11^{* * *}$ & 1 \\
Total & 31 & 19 & 34 & 13 & 14 \\
\hline
\end{tabular}

LC resin, light curing composite resin; RSC, resin strip crown; ZC, zirconia crown.

Fisher's exact test $\left({ }^{* *} p<0.001\right)$.

비해 생존에 유리하다고 할 수 있으며 특히 치수치료를 시행한 경우에는 더욱 resin strip crown이나 지르코니아 크라운이 유 리하다고 할 수 있다. 하지만 치수치료가 필요하지 않고 크기가 작은 인접면 우식 병소의 경우 치질 삭제량이 적은 복합레진 또 한 수복 재료로 고려될 수 있을 것으로 생각된다. Croll과 Berg [11]는 중등도의 유전치부 인접면 우식은 복합레진을 사용하여 성공적으로 수복할 수 있다고 하였다.

우식이 근심면이나 원심면 중 한 면에만 국한된 경우와 근심 면과 원심면에 모두 발생한 경우로 나누어 각 재료별 24 개월 생 존율을 분석하였을 때 복합레진 수복의 경우 한 면에만 국한된 경우에는 $42.9 \%$ 의 실패율을 보인 반면 양면에 모두 이환된 경 우 59.6\%로 높은 실패율을 보였다. 그러나 resin strip crown 과 지르코니아 크라운의 경우 실패율의 차이를 보이지 않아 여 러 면에 이환된 유전치부 우식의 경우 복합레진의 수복보다는 resin strip crown이나 지르코니아 크라운이 보다 나은 결과를 보였다. 이는 더 많은 치아면이 우식에 이환될수록 크라운의 실 패 확률도 높다는 Ram과 Fuks [12]의 연구와는 상반된다. 하 지만 우식 부위만을 부분적으로 제거하고 수복하는 복합레진 수복에 비해 전체 치아 면을 일부 삭제하여 치관을 덮어쓰우는 resin strip crown이나 지르코니아 크라운의 수복이 우식에 이 환된 면의 수에 영향을 덜 받는 것은 합리적인 결과로 생각된다.

수복 재료에 따른 실패의 종류에도 차이를 보였는데 이는 각 재료별 장단점을 잘 반영하고 있다. 복합레진 수복의 경우 이차 우식과 수복물의 탈락이, resin strip crown의 경우 수복물의 파절과 탈락이 가장 많았으며 지르코니아 크라운은 치경부 파 절이 가장 많이 나타났다. 전치부 복합레진 수복 시 가장 주요 한 실패 양상으로 Demarco 등[13]은 이차우식과 수복물의 파 절을 언급하였으나 이는 영구치를 대상으로 한 연구였으며 $\mathrm{Ku}-$ pietzky 등[14]은 resin strip crown의 가장 주요한 실패 양상 으로 수복물의 파절을 언급하여 본 연구의 결과와 유사하였다. Seminario 등[9]의 연구에 따르면 상악 유전치부의 지르코니아 크라운시 가장 빈발하는 합병증은 근단병소로 나타나 본 연구
와는 차이를 보였는데 추적관찰 기간이 3년으로 본 연구와는 차 이가 있었다.

본 연구에서는 470 여 개의 표본을 조사하여, 상악 유절치부 의 인접면 우식 처치 시 재료의 선택에 도움이 될 만한 결과를 도출하였다고 생각된다. 하지만 후향적 연구의 특성상 여러 명 의 소아치과 의사들이 수행한 수복 치료를 전자의무기록과 방 사선 사진으로 평가 및 연구하였기 때문으로 와동의 형태와 치 아의 삭제 정도를 정확하게 파악하는 것이 불가능하였다. 또한 우식의 정도를 통제하지 못한 점도 아쉬운 점이었다. 임상가는 우식의 정도를 고려하여 수복 방법을 고려하게 되므로 수복 재 료 간 정확한 비교를 위해서는 향후 유사한 우식 정도를 가지는 치아에 대한 수복재료의 비교 연구가 필요할 것으로 생각된다.

\section{ACKNOWLEDGEMENTS}

This study was supported by research fund from Chosun University, 2016.

\section{CONFLICTS OF INTEREST}

The authors declare that they have no competing interests.

\section{ORCID}

\author{
Doo-Soo Kim \\ https://orcid.org/0000-0002-9903-2744 \\ Nan-Young Lee \\ https://orcid.org/0000-0002-4738-9389 \\ Myeong-Kwan Jih \\ https://orcid.org/0000-0001-9579-076X
}




\author{
Ok-Hyung Nam \\ https://orcid.org/0000-0002-6386-803X
}

\section{REFERENCES}

1. Anil S, Anand PS. Early childhood caries: prevalence, risk factors, and prevention. Front Pediatr 2017;5:157. doi: 10.3389/fped.2017.00157.

2. Duhan H, Pandit IK, Srivastava N, Gugnani N, Gupta M, Kochhar GK. Clinical comparison of various esthetic restorative options for coronal build-up of primary anterior teeth. Dent Res J (Isfahan) 2015;12:574-580. doi: 10.4103/1735-3327.170578.

3. Waggoner WF. Restoring primary anterior teeth. Pediatr Dent 2002;24:511-516.

4. Usha M, Deepak V, Venkat S, Gargi M. Treatment of severely mutilated incisors: a challenge to the pedodontist. J Indian Soc Pedod Prev Dent 2007;25 Suppl:S34-S36.

5. Mortada A, King NM. A simplified technique for the restoration of severely mutilated primary anterior teeth. J Clin Pediatr Dent 2004;28:187-192. doi: 10.17796/ jcpd.28.3.2554xv412644ru13.

6. Tran LA, Messer LB. Clinicians' choices of restorative materials for children. Aust Dent J 2003;48:221-232. doi: 10.1111/j.1834-7819.2003.tb00035.x.

7. Lee JK. Restoration of primary anterior teeth: review of the literature. Pediatr Dent 2002;24:506-510.

8. Berg JH. Glass ionomer cements. Pediatr Dent 2002;24: 430-438.

9. Seminario AL, Garcia M, Spiekerman C, Rajanbabu P, Donly KJ, Harbert P. Survival of zirconia crowns in primary maxillary incisors at 12-, 24- and 36-month follow-up. Pediatr Dent 2019;41:385-390.

10. Korean Academy of Pediatric Dentistry. Textbook of pediatric dentistry. 5th ed. Seoul: Yenang Inc; 2014;100.

11. Croll TP, Berg J. Simplified primary incisor proximal restoration. Pediatr Dent 2003;25:67-70.

12. Ram D, Fuks AB. Clinical performance of resin-bonded composite strip crowns in primary incisors: a retrospective study. Int J Paediatr Dent 2006;16:49-54. doi: 10.1111/ j.1365-263X.2006.00680.x.

13. Demarco FF, Collares K, Coelho-de-Souza FH, Correa MB, Cenci MS, Moraes RR, Opdam NJ. Anterior composite restorations: a systematic review on long-term survival and reasons for failure. Dent Mater 2015;31:1214-1224. doi: 10.1016/j.dental.2015.07.005.

14. Kupietzky A, Waggoner WE, Galea J. Long-term photographic and radiographic assessment of bonded resin composite strip crowns for primary incisors: results after 3 years. Pediatr Dent 2005;27:221-225. 